Pesq. Vet. Bras. 37(4):401-407, abril 2017 DOI: $10.1590 /$ S0100-736X2017000400016

\title{
Morphological evaluation of the thoracic, lumbar and sacral column of the giant anteater (Myrmecophaga tridactyla Linnaeus, 1758) ${ }^{1}$
}

\author{
Naida C. Borges ${ }^{2}$, Viviane S. Cruz ${ }^{3}$, Nadine B. Fares ${ }^{4}$, Júlio R. Cardoso ${ }^{3}$ \\ and Nathália Bragato ${ }^{5 *}$
}

\begin{abstract}
Borges N.C., Cruz V.S., Fares N.B., Cardoso J.R. \& Bragato N. 2017. Morphological evaluation of the thoracic, lumbar and sacral column of the giant anteater (Myrmecophaga tridactyla Linnaeus, 1758). Pesquisa Veterinária Brasileira 37(4):401407. Escola de Veterinária e Zootecnia, Universidade Federal de Goiás, Campus Samambaia, Avenida Esperança s/n, Campus Universitário, Goiânia, GO 74690-900. Brazil. E-mail: nathaliabragato@yahoo.com.br

This study aimed to describe the number of thoracic, lumbar and sacral vertebrae in tridactyla through radiographic examinations associated with gross anatomy determination. For this purpose, 12 adult specimens of $M$. tridactyla were analyzed, assigned to the Screening Center of Wild Animals (CETAS), IBAMA-GO, and approved by the Ethics Committee on the Use of Animals (Process CEUA-UFG nr 018/2014). In the radiographic examinations the following numbers of thoracic $(\mathrm{T})$ and lumbar $(\mathrm{L})$ vertebrae were observed: $16 \mathrm{Tx} 2 \mathrm{~L}$ $(\mathrm{n}=7), 15 \mathrm{~T} \times 2 \mathrm{~L}(\mathrm{n}=3)$, and $15 \mathrm{Tx} 3 \mathrm{~L}(\mathrm{n}=2)$. In contrast, the numbers of vertebrae identified by anatomical dissection were as follows: $16 \mathrm{Tx} 2 \mathrm{~L}(\mathrm{n}=4), 15 \mathrm{Tx} 2 \mathrm{~L}(\mathrm{n}=3)$, and $15 \mathrm{Tx} 3 \mathrm{~L}(\mathrm{n}=5)$. This difference occurred in cases of lumbarization of thoracic vertebrae, as seen in three specimens, and was explained by changes in regional innervations identified by anatomical dissection and the presence of floating ribs (right unilateral=1, left unilateral=1 and bilateral=1), which were not identified by radiographic exams. Regarding the sacral vertebrae there was no variation depending on the methods used, which allowed the identification of $4(n=1)$ or $5(n=11)$ vertebrae. Thus, we concluded that there is variation in the number of thoracic, lumbar and sacral vertebrae, in addition to lumbarization, which must be considered based on the presence of floating ribs, in this species.
\end{abstract}

INDEX TERMS: Thoracic column, lumbar column, sacral column, giant anteater, Myrmecophaga tridactyla, anatomical counting, radiographic, vertebrae, Xenarthra.

RESUMO.- [Avaliação morfológica da coluna torácica, lombar e sacral do tamanduá-bandeira (Myrmecophaga tridactyla Linnaeus, 1758).] Este estudo teve como ob-

\footnotetext{
${ }^{1}$ Received on April 18, 2016.

Accepted for publication on September 4, 2016

${ }^{2}$ Departamento de Medicina Veterinária (DMV), Escola de Veterinária e Zootecnia (EVZ), Universidade Federal de Goiás (UFG), Campus Samambaia, Av. Esperança s/n, Campus Universitário, Goiânia, GO 74690-900, Brazil.

${ }^{3}$ Instituto de Ciências Biológicas (ICB), UFG, Av. Esperança s/n, Campus Samambaia (Campus II), Goiânia, GO 74690-900, Brazil

${ }^{4}$ Residente da EVZ-UFG, Campus Samambaia, Av. Esperança s/n, Campus Universitário, Goiânia, GO 74690-900, Brazil.

${ }^{5}$ Doutorando de Zootecnia, EVZ-UFG, Campus Samambaia, Av. Esperança s/n, Campus Universitário, Goiânia, GO 74690-900, Brazil. *Corresponding author: nathaliabragato@yahoo.com.br
}

jetivo descrever o número de vértebras torácicas, lombares e sacrais em Myrmecophaga tridactyla por meio de exames radiográficos e por contagem anatômica. Foram analisados doze espécimes adultos de $M$. tridactyla oriundos do Centro de Triagem de Animais Silvestres (CETAS), IBAMA-GO, após aprovação pela Comissão de Ética no Uso de Animais (Processo CEUA-UFG no. 018/2014). Nos exames radiográficos, foram observados os seguintes números de vertebras torácicas (T) e lombares (L): 16Tx2L ( $\mathrm{n}=7), 15 \mathrm{Tx} 2 \mathrm{~L}(\mathrm{n}=3)$, e 15Tx3L ( $\mathrm{n}=2)$. Em contraste, o número de vértebras identificados através de dissecção anatómica foram como se segue: $16 \mathrm{Tx} 2 \mathrm{~L}(\mathrm{n}=4), 15 \mathrm{Tx} 2 \mathrm{~L}(\mathrm{n}=3)$, e 15Tx3L $(\mathrm{n}=5)$. Essa diferença ocorreu em casos de lombarização da vertebra torácica, como visto em três exemplares e, foi explicada por mudanças nas inervações regionais identificadas por meio 
de dissecção anatômica e a presença de costelas flutuantes (unilateral direita $=1$, unilateral esquerda $=1$ e bilateral $=1$ ) que não foram identificados por meio de exame radiográfico. Em relação ao número de vértebras sacrais não houve variação dos métodos utilizados, sendo que ambos permitiram a identificação de quatro $(\mathrm{n}=1)$ ou $5(\mathrm{n}=11)$ vértebras. Assim, concluiu-se que há variação no número de vértebras torácicas, lombares e sacrais, devido à lombarização, que devem ser consideradas com base na presença de costelas flutuantes nesta espécie.

TERMOS DE INDEXAÇÃO: Coluna torácica, coluna lombar, coluna sacral, tamanduá-bandeira, Myrmecophaga tridactyla, contagem anatômica, radiografia, vértebras, Xenarthra.

\section{INTRODUCTION}

The Superorder Xenarthra $($ xeno $=$ strange and arthron = joint) comprises armadillos (order Cingulata), anteaters and sloths (order Pilosa) (Vizcaíno \& Loughry 2008).

The giant anteater (Myrmecophaga tridactyla) is a fossorial plantigrade mammal and is classified as "vulnerable" by the International Union for Conservation of Nature and Natural Resources (IUCN) of 2014. These animals are quadrupeds, but they can develop a semierect position using their pelvic muscles and tail. This attitude is observed during expeditions in search for food, such as termites or ants, or when defending themselves. Anteaters are affected by various types of clinical disorders; in both their habitat and captivity, however, trauma is among the most common causes of disease in this species (Cruz et al. 2013).

For many years, the study of these animals has been mainly restricted to their ecology and behavior. Nevertheless, the care of wildlife has become routine in veterinary hospitals and clinics around the world, necessitating veterinary clinicians, surgeons and anesthesiologists to acquire deeper knowledge of the morphology of anteaters to provide better care for these animals, culminating in a higher survival rate, which favors the preservation of the animal. Radiology enables veterinary clinicians and surgeons to diagnose many common conditions in wildlife, especially those that have suffered trauma, and to use the surgical technique that results in the best treatment.

Some papers have reported the number of vertebrae in this species, although the number of specimens used was restricted, and the only method used was counting; additionally, these reports contained no references to the number of sacral vertebrae and/or ribs (Flower 1985, Sánchez-Villagra \& Narita 2007, Endo et al. 2009, Cruz et al. 2014).

Therefore, we performed an anatomical and radiographic study of the thoracic vertebral column associated with the ribs, lumbar and sacral vertebrae of the giant anteater (Myrmecophaga tridactyla), using different counting techniques to determine the numbers of vertebrae and their conformations.

\section{MATERIALS AND METHODS}

Twelve adult specimens of Myrmecophaga tridactyla, six males and six females were analyzed. These animals were donated to the Screening Center of Wild Animals in Goiás (CETAS-GO) by the
Brazilian Institute of the Environment (IBAMA). The carcasses were received after natural death; no animals were euthanized. The CETAS/IBAMA are the wildlife rehabilitation centers that receive animals that are rescued after accidents in nature and require care for any reason.

The experiment was previously approved by Ethics Committee on the Use of Animals (number 018/2014). The preparation, accommodation and dissection were performed at the Animal Anatomy Laboratory of the Biological Sciences Institute (ICB) of the Federal University of Goiás (UFG).

After the specimens were received, they were defrosted at room temperature $\left( \pm 25^{\circ} \mathrm{C}\right)$ for 48 hours, cleaned under running water and submitted to fixation with injections of $10 \%$ formaldehyde corresponding to $10 \%$ of their body weight. Then, they were immersed in $4 \%$ formaldehyde solution for at least 72 hours of fixation (Rodrigues 2010).

The dissection of the soft tissues of the thoracic, abdominal and pelvic regions was conducted after these regions were accessed via a longitudinal incision along the linea alba, followed by the removal of the pubis, pelvic symphysis and genitourinary organs. The specimens were ordered sequentially and sent to the Diagnostic Imaging Sector of the Veterinary Hospital in the School of Veterinary and Zootechnics (EVZ) of the Federal University of Goiás (UFG) to perform a radiographic examination in ventrodorsal (VD) and laterolateral (LL) projections.

The devices used were a X-ray device by Tur in the T-350 model (Röntgentechnik GmbH, Potsdam, Germany) with the capability for $600 \mathrm{~mA}$ and a Potter-Bucky antiscatter grid. Radiographic film (T-MAT, Kodak, Brazil) was placed in $30 \mathrm{~cm} \times 40 \mathrm{~cm}$ chassis equipped with intensifying screens. The radiographic technique adopted was $\pm 30 \mathrm{kV}, 20 \mathrm{mAs}$, and the focus-film distance was 90 $\mathrm{cm}$. The radiographs were analyzed according to Thrall (2011).

Afterwards, the specimens were returned to the Animal Anatomy Laboratory and were dissected according to Rodrigues (2005). The numbers of thoracic, lumbar and sacral vertebrae, as well as the numbers of ribs, were anatomically recorded in all specimens As an additional criteria for the vertebrae classification, it was used the territory of distribution of the spinal nerves as a resource to distinguish true thoracic vertebrae from the lumbar vertebrae holding lumbar ribs, once in this last case, the trajectory and nerve distribution follows that of the typical lumbar nerves (Cruz et al. 2014).

For skeleton preparation, two non-fixed carcasses were submitted to manual evisceration and flesh removal by using knives, scalpels and tweezers. Then, the skeleton was disarticulated; the bone parts were boiled in hot water for about an hour and washed with a brush. The bone degreasing was carried out by immersion in petroleum ether for 10 minutes. Afterwards, the bones were immersed in hydrogen peroxide (15 volume strength) until they bleached white (around 4 hours). The articulation of the bones was carried out by using galvanized wire and cutting ant tying tools. We also used two skeletons from the collection of the Museum of Morphology of the ICB-UFG.

The findings were documented by photographs taken with a digital camera (Sony DSC-H50, Brazil). The nomenclature used to describe the results is in accordance with that proposed by the International Committee on Veterinary Gross Anatomical Nomenclature (2012).

\section{RESULTS}

The number of thoracic, lumbar and sacral vertebrae and the number of ribs were determined using two methods. The first was radiographic study to analyze the morphology of each vertebral segment, followed by gross anatomy 
determination, which considered the observed morphology of each segment. In these animals, the origins and distributions of the spinal nerves were dissected, as it may be possible to associate morphology with innervation to specify the number of vertebrae and ribs.

For the radiographic examination, landmarks were established in the ventrodorsal and laterolateral projections to standardize the assessment and counting of the vertebrae and ribs in this species. Upon morphological comparisons with other animal species, anatomical differences were observed in the vertebral column regarding the numbers and shapes of the vertebrae, as well as the presence of hemi- and floating ribs.

Each vertebra (last thoracic and lumbar) has a spinous process, two transverse processes and two xenarthrans processes. The spinous processes of the sacral vertebrae are fused (Fig.1). The vertebral bodies have the same basic characteristics as those of domestic animals. Counting of ribs and thoracic vertebrae was performed using a radiographic examination in the LL projection, using the rib joint and the cranial portion of the vertebral body as a reference (costochondral joint) (Fig.2).

On a VD projection (Fig.3), the first lumbar vertebra (L1) was identified after the last thoracic vertebra with its respective rib. The first sacral vertebra (S1) was determined by the joint with the ilium, and the number of sacral vertebrae corresponded to the number of intervertebral foramina. The first coccygeal (Cc1) vertebra was visualized articulating with the ischium and morphologically had a larger body and larger transverse processes than the other vertebrae.

The fusion of the spinal processes of the sacral vertebrae was used as a reference for the pelvic region in the LL projection on radiography. The fusion lines delimit the lumbar vertebrae cranially and the coccygeal vertebrae caudally (Fig.4).

Floating ribs were observed on radiographic examination and in the carcasses and skeletons of $25.0 \%$ of the specimens $(n=3)$ as follows: right unilateral $(n=1)$, left unilateral $(n=1)$ and bilateral $(n=1)$. The mean number of floating ribs on radiographic examination was as follows: 16 ribs and 16 thoracic, 2 lumbar and 5 sacral vertebrae, whereas 15 ribs and 15 thoracic, 3 lumbar and 5 sacral vertebrae were found on gross anatomy evaluation. The specimen that had a right unilateral floating rib was observed to have 16 right ribs and 15 left ribs, and the specimen that had a left unilateral floating rib was found to have 16 left ribs and 15 right ribs. This occurred because the number of ribs was greater on the side where the floating rib was located; the other side did not have a corresponding rib.

The mean number of thoracic vertebrae on radiographic examination was 15 for $41.6 \%(n=5)$ or 16 for $58.3 \%$ $(n=7)$ of specimens, and the number of lumbar vertebrae was 2 for $83.3 \%(n=10)$ or 3 for $16.6 \%(n=2)$ of specimens, corresponding to medians of $15.58 \pm 0.51$ thoracic vertebrae (T) and 2.7 \pm 0.39 lumbar vertebrae (L). The correlation between the numbers of the two vertebral segments observed on radiography was $16 \mathrm{~T}$ and $2 \mathrm{~L}$ in $58.3 \%(\mathrm{n}=7)$, $15 \mathrm{~T}$ and $3 \mathrm{~L}$ in $16.6 \%(\mathrm{n}=2)$ and $15 \mathrm{~T}$ and $2 \mathrm{~L}$ in $25.0 \%(\mathrm{n}=3)$.
The number of sacral vertebrae found in the specimens was as follows: 4 in $8.3 \%(n=1)$ and 5 in $91.6 \%(n=11)$ of specimens, with a median of $4.92 \pm 0.29$ sacral vertebrae. The number of ribs counted with that method was 16 in $58.3 \%(n=7)$ and 15 in $41.6 \%(n=5)$ of specimens, with a median of $15.58 \pm 0.51$ ribs.

For anatomic analysis, the same morphologic parameters cited in the radiographic examination were used. During anatomic dissection of the carcasses, it was observed that the thoracic nerves have multisegments and that the

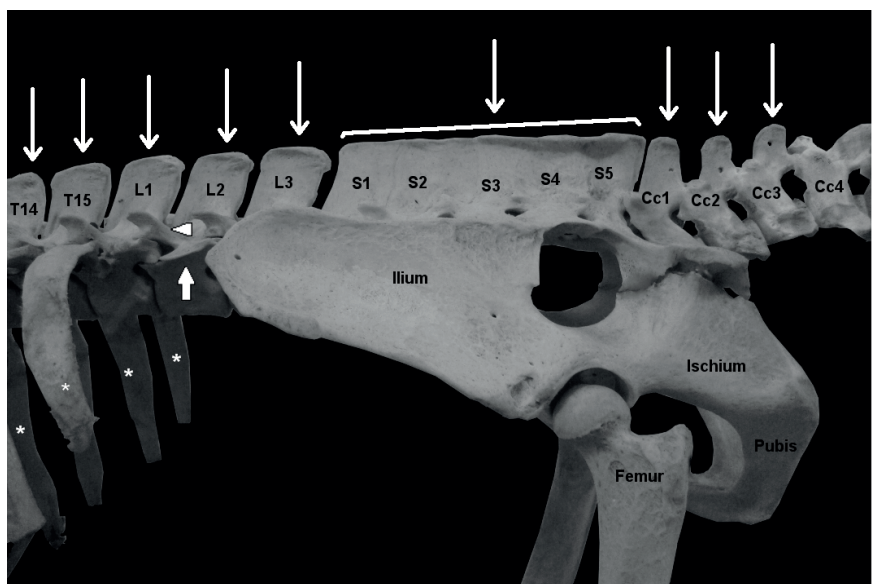

Fig.1. Lateral view of the pelvic region in a skeleton of a giant anteater. The thoracic (T14 to T15), lumbar (L1-L3), sacral (S1S5) and coccygeal (Cc1-Cc4) vertebrae are identified. Spinal process (thin arrows), transverse process (arrowhead), xenarthrans process (tick arrow), and ribs (asterisk).

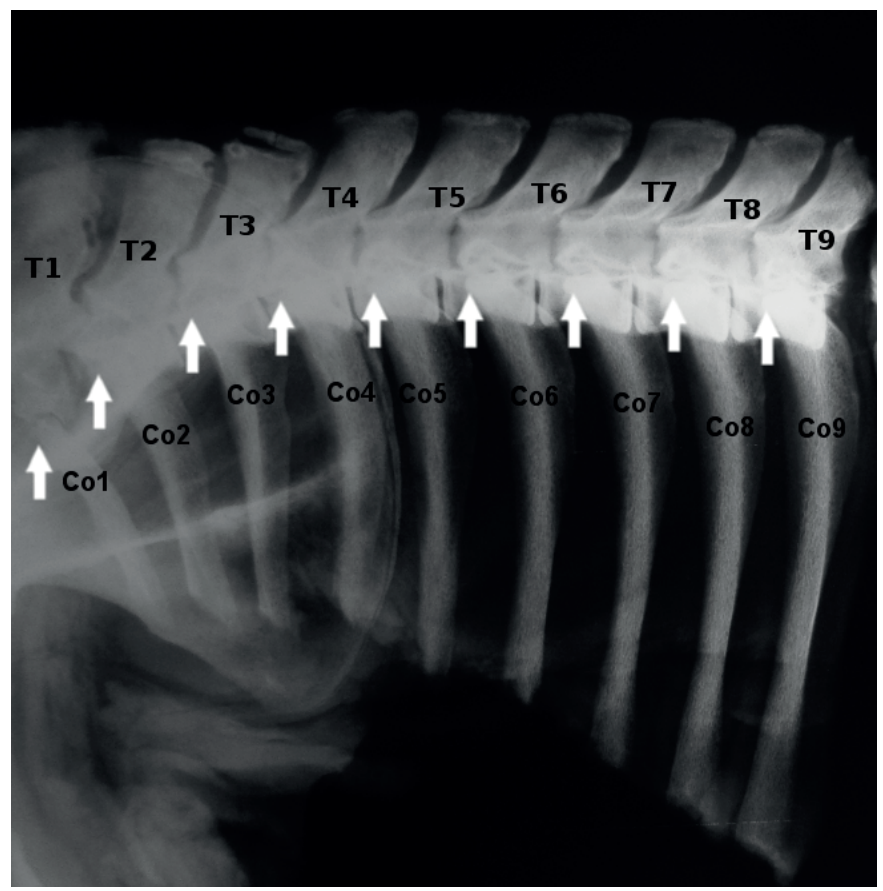

Fig.2. Radiograph in the laterolateral projection of the thoracic region in a specimen of giant anteater. The thoracic vertebrae (T1-T9) and ribs (Co1-Co9) are identified. The costochondral joints (arrows) were used as references to count the ribs and thoracic vertebrae in all specimens analyzed in the study. Radiograph data: $100 \mathrm{~mA}, 32 \mathrm{kV}, 0.200 \mathrm{~s}$ and $20 \mathrm{mAs}$. 


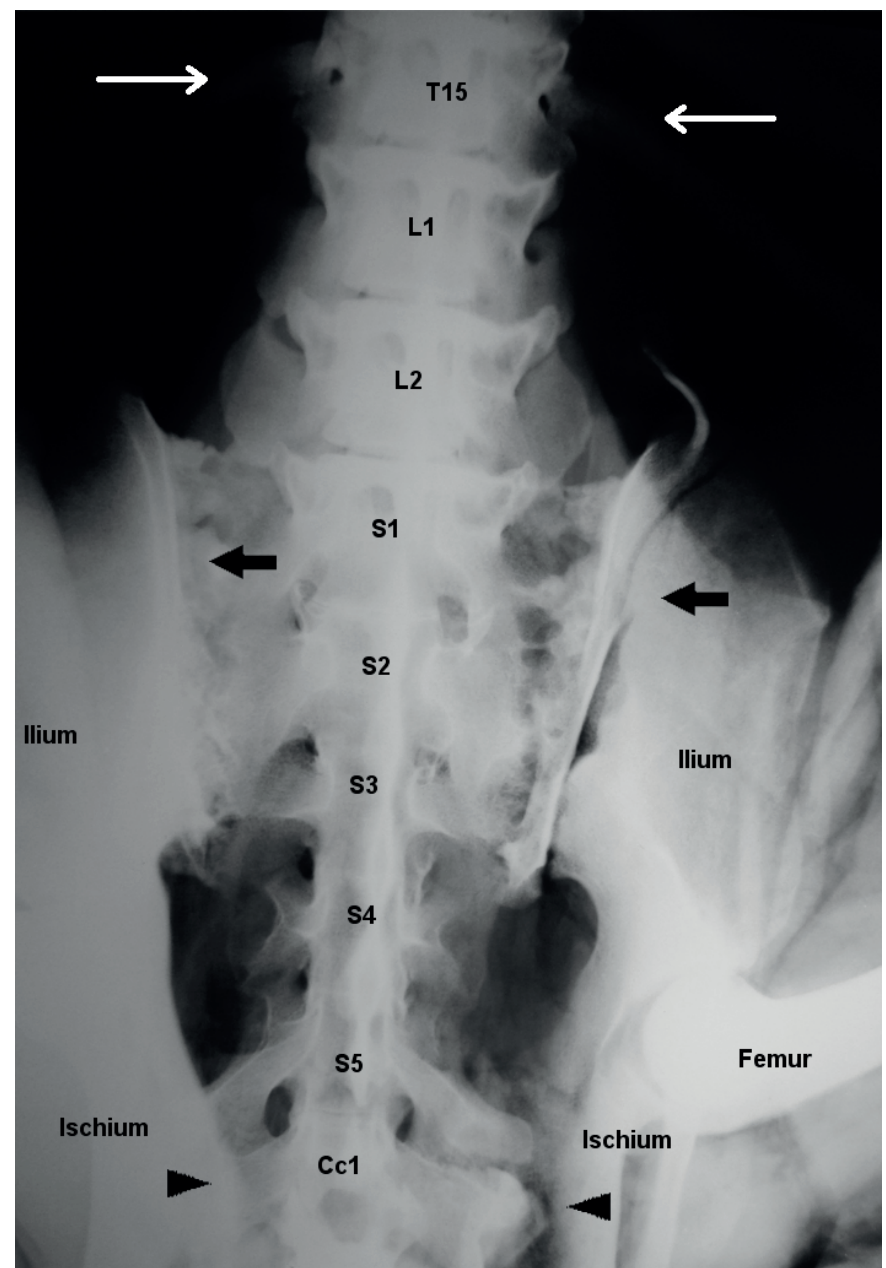

Fig.3. Radiograph in the ventrodorsal projection of the pelvic region in a specimen of giant anteater. The thoracic (T15), lumbar (L1 and L2), sacral (S1-S5) and coccygeal vertebrae (Cc1) are identified. The last thoracic vertebra (T15) was identified by visible ribs (thin arrows). Joints (arrows) of the first sacral vertebra (S1) with the ilium. Joints (arrowheads) of the first coccygeal vertebra (Cc1) with the ischium. Radiograph data: $100 \mathrm{~mA}, 32 \mathrm{Kv}, 0.200 \mathrm{~s}$ and $20 \mathrm{mAs}$.

lumbar plexus involved the last thoracic spinal nerve (T15 or T16) in $75.0 \%$ of specimens, whereas the sacral plexus involved the last lumbar spinal nerve (L2 or L3) in $75.0 \%$, the last two nerves (L2 and L3) in 16.6\% and involved no lumbar contribution in $8.3 \%$ of specimens. It was also observed that the spinal nerve that emerges from the caudal intervertebral foramen of the vertebrae with floating ribs (bilateral or unilateral) was similar in origin and innervation distribution to the first lumbar vertebra from the specimens that did not have floating ribs. In other words, this nerve completely participates in the lumbar plexus and does not contribute to the innervation of the abdominal wall. The spinal nerve cranial to this nerve (last thoracic nerve) bifurcates; the cranial segment descends parallel to the last rib, joining with the caudal segment of the penultimate intercostal nerve, known as the costoabdominal nerve, whereas the caudal segment descends to the lumbar segments to integrate with the nerves of lumbar plexus.

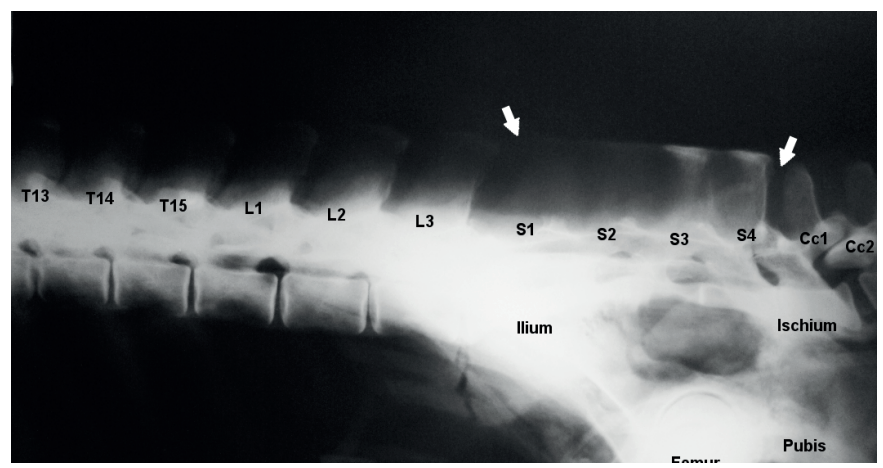

Fig.4. Radiograph in laterolateral projection of the pelvic region in a specimen of giant anteater. Thoracic (T13-T15), lumbar (L1L3), sacral (S1-S4) and coccygeal vertebrae (Cc1 and Cc2) are identified. The fusion lines (arrows) on the sacral vertebrae delimit the lumbar vertebrae cranially and the coccygeal vertebrae caudally. Radiograph data: $100 \mathrm{~mA}, 32 \mathrm{kV}, 0.200 \mathrm{~s}$ and $20 \mathrm{mAs}$.

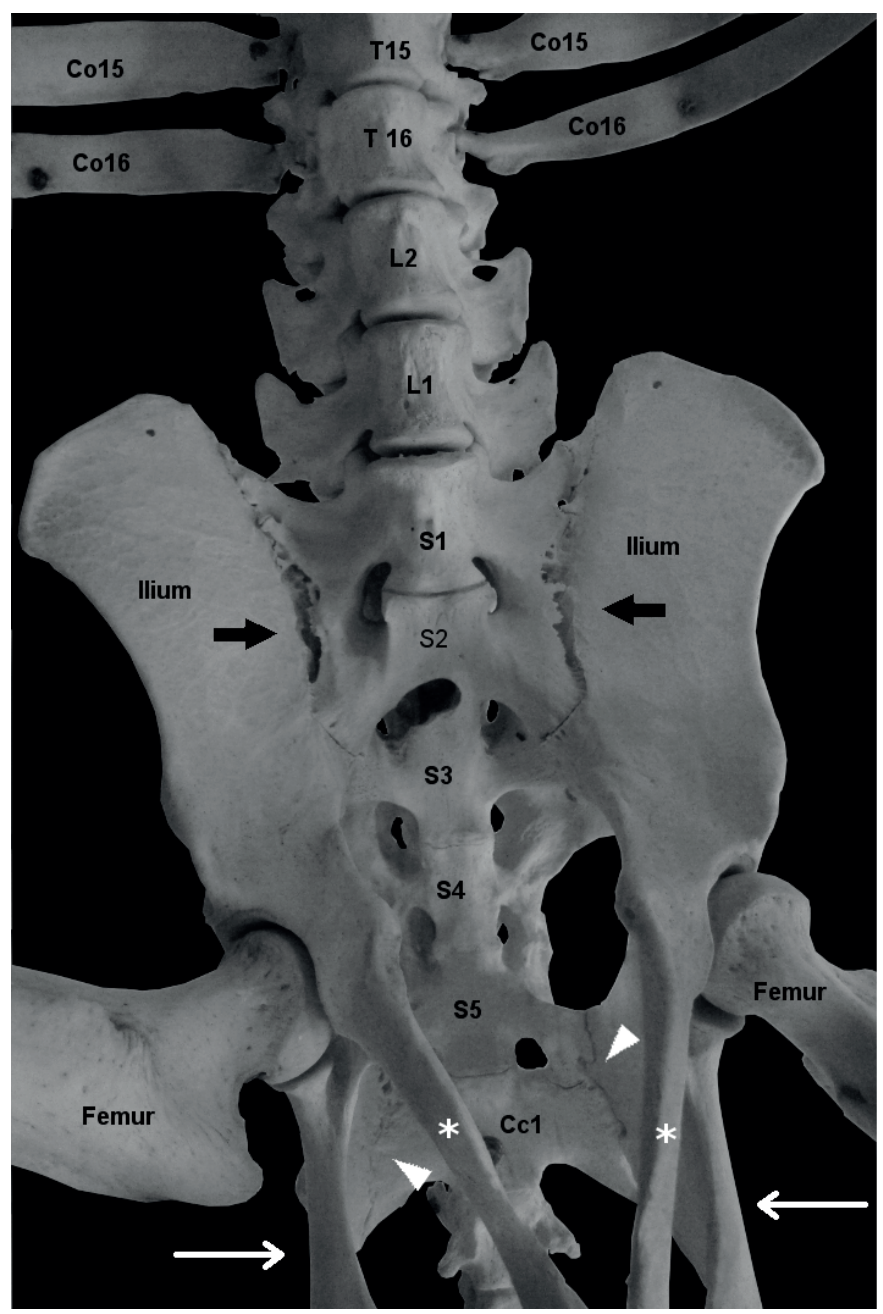

Fig.5. Ventrodorsal view of the pelvic region in a skeleton of a giant anteater. The thoracic (T15 and T16), lumbar (L1 and L2), sacral (S1-S5) and coccygeal vertebrae (Cc1) are identified. Joint (arrow) of the ischium with the transverse process of the first coccygeal vertebra ( $\mathrm{Cc} 1$ ), which is fused to the last sacral vertebra (S5). Ischium (thin arrows), pubis (asterisks) and ribs (Co16 and Co15). 
Thus, these vertebrae with floating ribs (unilateral or bilateral) were described as lumbar vertebrae (L1), a description that is explained by the reduced morphological development of the ribs and/or the unilateral absence of a rib that is associated with the morphology of the corresponding spinal nerve, a process known as the lumbarization of the last thoracic vertebra. Thus, these ribs present in a lumbarized thoracic vertebra would be denoted as lumbar ribs.

Thus, the anatomic findings were as follows: 15 thoracic vertebrae in $66.6 \%(n=8)$ and 16 in $33.3 \%(n=4)$ of specimens, for a median of $15.33 \pm 0.39$ thoracic vertebrae; 2 lumbar vertebrae in $58.3 \%(n=7)$ and 3 in $41.6 \%(n=5)$ of specimens, for a median of $2.42 \pm 0,51$ lumbar vertebrae; and 4 sacral vertebrae in $8.3 \%(n=1)$ and 5 in $91.6 \%(n=11)$ of specimens, for a median of $4.92 \pm 0.29$ sacral vertebrae. The numbers of ribs counted with this method were 16 in $33.3 \%(n=4)$ and 15 in $66.7 \%(n=8)$ of specimens, with a median of $15.33 \pm 0.49$ ribs.

In individuals without floating ribs $(75.0 \%)$, the following numbers of vertebrae were recorded both radiographically and anatomically: 15 (55.5\%) and 16 (44.4\%) ribs; two $(77.7 \%)$ and three $(22.2 \%)$ lumbar vertebrae; $15(55.5 \%)$ and $16(44.4 \%)$ thoracic vertebrae; and four $(11.1 \%)$ and five $(88.8 \%)$ sacral vertebrae.

The relationship between the number of thoracic and lumbar vertebrae varied according to the procedure performed. Using radiographic observation, 16Tx2L $(n=7)$, 15Tx2L $(n=3)$, and 15Tx3L $(n=2)$ vertebrae were verified. In contrast, anatomical dissection revealed $16 \mathrm{Tx} 2 \mathrm{~L}(\mathrm{n}=4)$, 15Tx2L $(n=3)$, and 15Tx3L $(n=5)$ vertebrae. The differences between the radiographic and anatomic findings for the number of thoracic and lumbar vertebrae are presented in Table 1.

\section{DISCUSSION}

The constitution of the spinal nerve is correlated with its origin in the medullar segment and its posterior course through the corresponding intervertebral foramen. Thus, previous knowledge regarding the number of vertebrae is needed to determine this origin. According to Flower and other authors (Flower 1985, Sánchez-Villagra \& Narita 2007, Endo et al. 2009, Cruz et al. 2014), the numbers of thoracic, lumbar and sacral vertebrae are variable in the giant anteater; however, these authors did not report the presence of bilateral or unilateral floating ribs.

Flower (1985) and Cruz et al. (2014) report Myrmecophaga tridactyla with 16 thoracic vertebrae have two lumbar vertebrae and that specimens with 15 thoracic vertebrae have three lumbar vertebrae, which was confirmed by the results of this study, which noted these findings in most specimens $(75.0 \%)$. Fifteen thoracic vertebrae and two lumbar vertebrae were found in three animals $(25.0 \%)$. It was observed that there was a proportional increase in the number of specimens with 15 thoracic and two lumbar vertebrae in this study when using a greater number of specimens compared with the $16.6 \%$ reported by Cruz et al. (2014). Regarding the sacral vertebrae, Flower (1985) reported the presence of three or five; however, Cruz et al. (2014) described four or five, which are the same numbers observed in this work but in a larger number of specimens (91.6\%). Cardoso et al. (2013) reported the presence of 18 thoracic, three lumbar and five sacral vertebrae in the collared anteater (Tamandua tetradactyla), which makes it possible to identify differences between species of anteaters by the number of vertebrae, especially in this region.

Through radiographic examination, this study verified that the vertebrae of the giant anteater along the spine have the same basic characteristics of the vertebral bodies described by Burk and Feeney ${ }^{11}$ for canine species and by Dyce et al. (2010) for bovine and equine species and that the presence of two transverse processes and two xenarthrans follows the pattern identified for all animals of the Superorder Xenarthra, agreeing with Endo et al. (2009), Nyakatura \& Fischer (2012) and Cruz et al. (2013).

Another peculiarity of this Superorder involves the presence of one joint between the transverse process of the first coccygeal vertebra, which is fused to the sacrum, and the ischium (Fig.5), a parameter used to help in counting the vertebrae of the vertebral column in Myrmecophaga tridactyla. (Nyakatura \& Fischer 2012).

The articulation between the first coccygeal vertebra and the last sacral vertebra in the giant anteater was visualized radiographically to be more caudal in the LL projection than in the dog. Because the vertebral body length is

Table 1. Number of ribs and vertebrae in twelve giant anteaters (Myrmecophaga tridactyla) and comparison with the number of vertebrae in other mammals described in the literature

\begin{tabular}{|c|c|c|c|c|c|c|c|c|}
\hline \multirow[t]{2}{*}{ Animal } & \multicolumn{2}{|c|}{ Ribs } & \multicolumn{2}{|c|}{ Thoracic vertebrae } & \multicolumn{2}{|c|}{ Lumbar vertebrae } & \multicolumn{2}{|c|}{ Sacral vertebrae } \\
\hline & $\mathrm{RX}$ & GA & RX & GA & $\mathrm{RX}$ & GA & $\mathrm{RX}$ & GA \\
\hline $\begin{array}{l}\text { Myrmecophaga tridactyla } \\
\text { Cães e gatos }\end{array}$ & $15.58 \pm 0.51$ & $15.33 \pm 0.49$ & $15.58 \pm 0.51$ & $15.33 \pm 0.49$ & $2.17 \pm 0.39$ & $2.42 \pm 0.51$ & $4.92 \pm 0.29$ & $4.92 \pm 0.29$ \\
\hline $\begin{array}{l}\text { (Sisson \& Grossman 1986) } \\
\text { Bovinos }\end{array}$ & - & 13 & - & 13 & - & 7 & - & 3 \\
\hline $\begin{array}{l}\text { (Sisson \& Grossman 1986) } \\
\text { Equinos }\end{array}$ & - & 13 & - & 13 & - & 6 & - & 5 \\
\hline $\begin{array}{l}\text { (Sisson \& Grossman 1986) } \\
\text { Tamandua tetradactyla }\end{array}$ & - & 18 & - & 18 & - & 6 & - & 5 \\
\hline $\begin{array}{l}\text { (Sesoko et al. 2011) } \\
\text { Dasypus novencinctus }\end{array}$ & - & 16 & - & 16 & - & 3 & - & 5 \\
\hline (Franzo et al. 2011) & - & 15 & - & 15 & - & 4 & - & 5 \\
\hline
\end{tabular}

Medians and standard deviations (SD) of the numbers of ribs and vertebrae in the thoracic, lumbar and sacral columns using radiography

(RX) and gross anatomy (GA) evaluations in M. tridactyla. 
more elongated and the number of sacral vertebrae is larger, the articulation of the last sacral vertebrae (S4 or S5) and the first coccygeal vertebra (Cc1) is located dorsal to the ischial tuberosity of the giant anteater. In the dog, this joint is located on the dorsal cranial portion of the rump, i.e., in the middle region of the pelvis (Burk \& Feeney 2003).

There are reports in the literature about the presence of cervical ribs in other species of mammals, such as humans (Silvestri et al. 2005) and dolphins (Fettuccia \& Simões 2004), and in reptiles, such as the teiidae lizards (Veronese \& Krause 1997) and Brazilosaurus sanpauloensis (Sedor \& Ferigolo 2001). These ribs receive this nomenclature because they are present in cervical vertebrae. In humans, the presence of these ribs is one of the causes of thoracic outlet syndrome (SDT) (Silvestri et al. 2005, Araújo et al. 2009).

Farrow (2005) describes the cranial lumbarization process, which occurs when the last thoracic vertebra assumes the characteristics of the first lumbar vertebra and may result in the loss of one or two ribs or present one or two hypoplastic ribs, which may explain the presence of floating ribs in the animals of this study.

However, in the radiographic studies that report this phenomenon, the tendency exists to designate thoracic vertebrae only by the presence of ribs, even if they are floating ribs, without considering other factors that may support the hypothesis that the innervation territories of spinal nerves correspond to medular segments. In an attempt to corroborate this hypothesis, and due to the changes observed in the vertebral segments of this species, our results are based on the examination of the relationship between macroscopic bones and peripheral innervation and radiographic analysis.

Cruz et al. (2014) described the lumbar and sacral plexus, with an emphasis on the origin of the nerves that compose Myrmecophaga tridactyla, and Cardoso et al. (2013) did so for the Tamandua tetradactyla species; both studies report the original source of the lumbar plexus as the last thoracic segment. This formation was also reported in the hedgehog (Aydin 2009) and may be associated with a reduced number of lumbar vertebrae in these species, as reported by Cruz et al. (2014).

The anatomical analysis showed that the thoracic nerves have multiple segments and that the spinal nerve that emerges from the intervertebral foramen caudal to the vertebra with floating ribs (bilateral or unilateral) is similar in origin and innervation distribution to the first lumbar vertebra of the specimens without floating ribs, in other words, this nerve completely participates in lumbar plexus formation and does not contribute to the innervation of the abdominal wall. The spinal nerve cranial to this (last thoracic nerve) bifurcates, and the cranial segment descends parallel to the last rib, joining with the caudal branch of the penultimate intercostal nerve, known as the costoabdominal nerve, whereas the caudal segment joins the lumbar segments to integrate with the lumbar plexus nerves, as described by Cruz et al. (2014).

The above findings represent the cranial lumbarization theory as described by Farrow (2005), where the last thoracic vertebra acquires the function of a lumbar vertebra and thus becomes part of the lumbar group, even if it has unilateral or bilateral floating ribs (hemi-ribs) that will be designated as lumbar ribs. This concept must be disseminated in radiology because traditionally, the presence of ribs, even floating ribs, is a determining factor in the characterization of thoracic vertebrae.

Following the definition of Bateson (1984), changes in vertebral counts are homeotic when one of the components of the axial skeleton assumes the morphological appearance and function of the structure immediately before or after it.

This work addresses the need for studies on specimens with floating ribs in the elucidation of cranial lumbarization to support radiographic examinations, which normally do not recognize this process.

This study showed the clinical and surgical importance of the knowledge of the anatomy of various species, particularly Myrmecophaga tridactyla, which is a species at risk of extinction that is frequently found in the care of emergency services in veterinary medicine.

\section{CONCLUSIONS}

The study of the vertebral column of Myrmecophaga tridactyla enabled the definition of land marks to enable the precise counting of vertebrae and ribs.

It was possible to show that members of this species possess variations in the number of thoracic, lumbar and sacral vertebrae.

This study clarified the occurrence of lumbarization in the last thoracic vertebra in specimens with bilateral or unilateral floating ribs.

The last thoracic vertebra that articulates with the floating ribs should be considered a lumbar vertebra due to the presence of lumbar innervation, and the ribs should be denoted as lumbar ribs.

\section{REFERENCES}

Araújo L.F.L., Moreschi A.H., Macedo G.B., Moschetti L., Machado E.L. \& Saueressig M.G. 2009. Fístula linfática após tratamento cirúrgico de síndrome do desfiladeiro torácico à direita. J. Bras. Pneumol. 35:388-391.

Aydin A. 2009. The dissemination of the pelvic limb nerves originating from the lumbosacral plexus in the porcupine (Hystrix cristata). Veterinární Medicína 54:333-339.

Bateson W. 1984. Materials for the study of variation treated with especial regard to discontinuity in the origin of species. MacMillan and Co, London.

Burk R.L. \& Feeney D.A. 2003. Small Animal Radiology and Ultrassonography: a diagnostic atlas and text. 3rd ed. W.B. Saunders, Missouri.

Cardoso J.R., Souza P.R., Cruz V.S., Benetti E.J., Silva M.S.B., Moreira P.C., Cardoso A.A.L., Martins A.K., Abreu T., Simões K. \& Guimarães F.R. 2013. Estudo anatômico do plexo lombossacral de Tamandua tetradactyla. Arq. Bras. Med. Vet. Zootec. 65:1720-1728.

Cruz V.S., Cardoso J.R., Araújo L.B.M., Souza P.R. \& Araújo E.G. 2013. Aspectos anatômicos dos nervos da coxa de tamanduá-bandeira (Myrmecophaga tridactyla Linnaeus, 1758). Biosci. J. 29:1275-1283.

Cruz V.S., Cardoso J.R., Araújo L.B.M., Souza P.R., Borges N.C. \& Araújo E.G. 2014. Aspectos anatômicos do plexo lombossacral de Myrmecophaga tridactyla (Linnaeus, 1758). Biosci. J. 30:235-244.

Dyce K.M., Sack W.O. \& Wensing C.J.G. 2010. Tratado de Anatomia Veterinária. 4th ed. Elsevier, Rio de Janeiro.

Endo H., Komiya T., Kawada S., Hayashida A., Kimura J., Itou T., Koie H. \& 
Sakai T. 2009. Three-dimensional reconstruction of the xenarthrous process of the thoracic and lumbar vertebrae in the giant anteater. Mammal. Study 34:1-6.

Farrow C.S. 2005. Veterinary Diagnostic Imaging: the dog and cat. Elsevier, New York.

Fettuccia D.C. \& Simões-Lopes P.C. 2004. Morfologia da coluna vertebral do boto-cinza, Sotalia guianensis (Cetacea, Delphinidae). Biotemas $17: 125-148$.

Flower W.H. 1885. An Introduction to the Osteology of the Mammalian. 3rd ed. MacMillan and Co, London.

Franzo V.S., Vulcani V.A., Artoni S.M.B., Gradela A. \& Barreiro F.R. 2011. Estudo da fórmula vertebral do tatu-galinha. Revta Cient. Eletr. Med. Vet. 17:1-7.

Nyakatura J.A. \& Fischer M. 2012. Functional morphology and three-dimensional kinematics of thoraco-lumbar region of the spine of the two-toed sloth. J. Exp. Biol. 213:4278-4290.

International Committee on Veterinary Gross Anatomical Nomenclature 2012. Nomina Anatomica Veterinária. 5th ed. World Association on Veterinary Anatomist, Knoxville. 177p.

Rodrigues H. 2010. Técnicas Anatômicas. 4ª ed. GM Gráfica e Editora, Vitória.
Sánchez-Villagra M.R., Narita Y. \& Kuratani S. 2007. Thoracolumbar Vertebral Number: first skeletal synapomorphy for Afroterian mammals. Systemat. Biodiversity 5:1-7.

Sedor F.A. \& Ferigolo J. 2001. A coluna vertebral de Brazilosaurus sanpauloensis (Shikama \& Ozaki, 1966) da formação Irati, Permiano da Bacia do Paraná (Brasil) (Proganosauria, Mesosauridae). Acta Biologica Paranaense 30:151-173.

Sesoko N.F., Bortolini Z., Merlini N.B., Evngelista F.C., Rahal S.C., Machado V.M.V. \& Teixeira C.R. 2011. Coluna vertebral de Tamanduá-mirim Tamandua tetradactyla. Med. Vet. 5:1-3.

Silvestri K., Wagner F. \& Dal Moro A.N. 2005. Tratamento cirúrgico da síndrome do desfiladeiro torácico por via supraclavicular: estudo série de casos. Arqs Catarin. Med. 34:92-96.

Sisson S. \& Grossman J.D. 1986. Anatomia dos Animais Domésticos. 5ํㅡㄹ ed. Guanabara Koogan, Rio de Janeiro.

Thrall D.E. 2011. Textbook of Veterinary Diagnostic Radiology. 6th ed. Elsevier, St Louis.

Veronese L.B. \& Krause L. 1997. Esqueleto pré-sacral e sacral dos lagartos teiídeos (Squamata, teiidae). Revta Bras. Zool. 14:15-34.

Vizcaíno S.F. \& Loughry W.J. 2008. The Biology of the Xenarthra. University Press of Florida, Gainesville. 